\title{
Tonal and syntactic correlates of focus perception in Greek and Russian
}

Olga Nikolaenkova

Lab of Phonetics \& Computational Linguistics, University of Athens, Greece

https://doi.org/10.36505/ExLing-2011/04/0026/000195

\begin{abstract}
The present paper reports on the way word order and tonal slope influence focus perception in Russian and Greek declaratives. Perception experiment was carried out in order to identify the impact falling tone slope and word order change have on focus identification. The speech material included manipulated stimuli with 5 and 3 different falling tone slopes for Russian and Greek respectively and involved 6 different word orders. The results of the perception test indicate that: (1) slope manipulation is a reliable focus indicator; (2) word order change is not sufficient for focus identification; (3) no major cross-language contrasts were observed.
\end{abstract}

Key words: focus, perception, tonal slope, Russian, Greek

\section{Introduction}

Local tonal expansion accompanied by post-focal tonal compression is widely accepted as one of the main tonal correlates of focus (Botinis 2003, Nikolaenkova 2010, Xu 2011). Having a closer look at focus production data though we identify focus-marking through gradient means such as duration, F0 timing etc. The goal of the present study is to reveal the complex nature of focus implementation strategy. Contrastive analysis of the tonal slope and word order change effects on focus perception in Russian and Greek will help us estimate how deep the influence of linear hierarchy on focus perception is.

\section{Methodology}

The experiment was based on an exclusively designed computer application. Each listener was instructed to click on the most prominent unit if any. The time interval between the stimuli was 1,5 sec. The experiment consisted of five sets, 18 stimuli each, for Russian and four sets for Greek repeated 10 times in random order. For Russian the experiment yielded 9000 responses (90 utterances x 10 repetitions x 10 informants). For Greek the experiment yielded 7200 responses (72 utterances x 10 repetitions x 10 informants).

\section{Speech material}

Speech material for the experiment consisted of a Russian declarative sentence «ma-RI-na MJA-la man-da-RI-ny / Marina was pressing the mandarins» and a Greek one «i me-LI-na MA-lo-ne ti-MAna-mu / Melina was arguing with my mother» (block letters mark the stressed syllables). Female native speakers of Russian and Greek

ExLing 2011: Proceedings of 4th Tutorial and Research Workshop on Experimental Linguistics, 25-27 May, Paris, France 
respectively were recorded in a sound treated booth at the University of Athens Phonetics Laboratory. The task was first to read the phrase aloud and then to answer three questions eliciting three focus placements Sfocus, VP-focus and O-focus always using exactly the same phrase. The speech material was recorded directly to computer disk using the PRAAT software package.

\section{Focus production data}

According to the production data from Russian and Greek (see Table 1) we should highlight the following:

focus was found to significantly influence both rising and falling tone speed in Greek while in Russian its impact was observed only in case of Sfocused utterance;

no direct linkage between focus application and rising-falling tone speed balance has been revealed;

VP-focus has been found having the opposite effect on tonal speed range as well as on the balance between rising and falling speed in both languages.

Table 1. Tonal rise and fall speed rates within the stressed syllable and the one following it as a function of focus placement (+/- focus) in Russian and Greek.

\begin{tabular}{|c|c|c|c|c|c|c|c|c|c|c|c|c|}
\hline \multirow{3}{*}{$\mathrm{Hz} / \mathrm{s}$} & \multicolumn{4}{|c|}{ Subject } & \multicolumn{4}{|c|}{ Verbal Phrase } & \multicolumn{4}{|c|}{ Object } \\
\hline & \multicolumn{2}{|c|}{$\mathrm{N}$} & \multicolumn{2}{|c|}{$\mathrm{F}$} & \multicolumn{2}{|c|}{$\mathrm{N}$} & \multicolumn{2}{|c|}{$\mathrm{F}$} & \multicolumn{2}{|c|}{$\mathrm{N}$} & \multicolumn{2}{|c|}{$\mathrm{F}$} \\
\hline & $\mathrm{Ru}$ & $\mathrm{Gr}$ & $\mathrm{Ru}$ & Gr & $\mathrm{Ru}$ & $\mathrm{Gr}$ & $\mathrm{Ru}$ & $\mathrm{Gr}$ & $\mathrm{Ru}$ & $\mathrm{Gr}$ & $\mathrm{Ru}$ & $\mathrm{Gr}$ \\
\hline $\begin{array}{l}\mathscr{D} \\
\tilde{2}\end{array}$ & 682 & 51 & 668 & 643 & 286 & 62 & 286 & 349 & 330 & 152 & 330 & 165 \\
\hline 产 & 125 & 307 & 668 & 1240 & 582 & 242 & 582 & 173 & 422 & 242 & 422 & 591 \\
\hline
\end{tabular}

\section{Manipulation}

In accordance with the goals of the perception experiment naturally produced neutral utterances went through tonal slope manipulations and word order manipulations.

Tonal slope has been edited within the first post-stressed syllable through adjusting the speed of the tone. This set consisted of fifteen and nine stimuli for each utterance in Russian and Greek respectively. The slope observed for the falling tone in cases of natural focus productions was the reference point for further $30 \%$ step increase and decrease aimed at perception threshold identification. Word order manipulated stimuli involved lexical units being 
Tonal and syntactic correlates of focus perception in Greek and Russian 109

cut and dislocated. All the manipulated material went through tonal normalization.

\section{Results and Discussion}

The perception test showed that in total focus identification was $100 \%$ in Russian while in Greek it was 33\% (see Table 2). The reason for such contrast could be the fact that the Russian part involved two more slopes.

It is remarkable that in both languages successful identification rates were higher for $\mathrm{V}$ focus, while $\mathrm{S}$ focus had the lowest identification rate (see Table 2). This finding disagrees with our previous focus perception tests where VP and O focus (Nikolaenkova 2009). Having performed one-way ANOVA test with focus type as independent variable, we found that the effect of focus type on successful identification was statistically insignificant for both languages $(\mathrm{p}>0.05)$.

Table 2. Total successful focus identifications as a function of focus type in Russian and Greek.

\begin{tabular}{|l|c|c|c|c|c|c|}
\hline \multirow{2}{*}{ Focus Type } & \multicolumn{2}{|c|}{ S } & \multicolumn{2}{c|}{ V } & \multicolumn{2}{c|}{ O } \\
\cline { 2 - 7 } & Rus & Gr & Rus & Gr & Rus & Gr \\
\hline Success & 2110 & 400 & 4150 & 1040 & 2740 & 940 \\
\cline { 2 - 7 }$\%$ Success & 23.44 & 5.56 & 46.11 & 14.44 & 30.44 & 13.06 \\
\hline
\end{tabular}

On the other hand distribution of the parameters used in manipulating our stimuli neither revealed any tendency (see Figure 1). Nevertheless slope parameter, if accounted in total, has a significant domination of $74.84 \%$ $(\mathrm{p}<0.01)$ and $15 \%(\mathrm{p}<0.01)$ in Russian and Greek respectively.

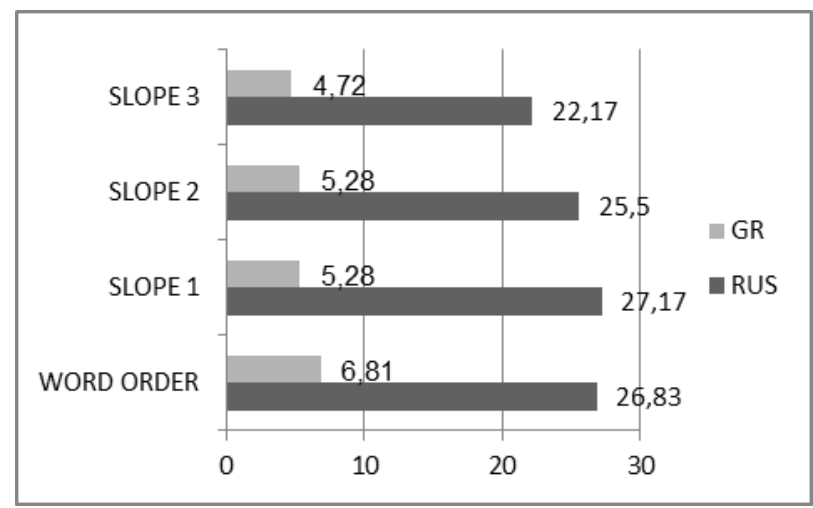

Figure 1. Successful focus identification percentages as a function of manipulation parameters in Russian and Greek. 
Having analysed the impact of word order and slope on focus identification separately we should acknowledge the leading role of slope in sounding speech. This conclusion is supported not only by the difference in successful identification rates of word order and slope taken separately but also by almost no change in identification rates in cases when both correlates have been applied. This almost invisible position of word order manipulation performs a strong argument in favour of ending the prevailing linear perception in studying focus.

\section{Acknowledgements}

I would like to thank P. Karamolenkos for the programming and testing of the relative application. My deep gratitude to all those who participated in the experiment and to those who gave me their kind guidance and advisory.

\section{References}

Botinis, A. 2003. Focus and gender tonal interactions. XVth International Congress of Phonetic Sciences, 1826-1829. Barcalona, Spain.

Nikolaenkova, O. 2009. Rhythmic and tonal correlates of focus in Greek. Master dissertation. University of Skovde, Sweden.

Nikolaenkova, O. 2010. Perception of «tonal focus» in Greek. Botinis, A. (ed.), Proc. of 3rd ISCA Workshop on Experimental Linguistics ExLing 2010, 121-124.

$\mathrm{Xu}, \mathrm{Y}$., Chen, S., Wang, B. Forthcomming. Prosodic focus with and without postfocus compression: A typological divide within the same language family? 